\title{
Mineração
}

\section{Concentração de finos provenientes da planta de beneficiamento do minério de manganês da Mineração Morro da Mina/ RDM por mesa oscilatória}

\author{
Érica Linhares Reis \\ Mestranda do Programa de Pós-Graduação em Engenharia Mineral \\ E-mail:ericasier@bol.com.br \\ Rosa Malena Fernandes Lima \\ Professora Adjunta do Departamento de Engenharia de Minas/EM/UFOP \\ E-mail:rosa@demin.ufop.br
}

\section{Resumo}

Esse artigo apresenta estudos de concentração de finos de minério de manganês (estocados como rejeito) da Mineração Morro da Mina/RDM em mesa oscilatória, visando à obtenção de concentrados para serem empregados na indústria metalúrgica. Os teores de $\mathrm{Mn}$, na amostra global e nas frações acima e abaixo de $0,074 \mathrm{~mm}$, eram de 28,$30 ; 26,84$ e $31,31 \%$, respectivamente. Pela análise granulométrica, verificou-se que $80 \%$ desses finos encontravam-se abaixo de $0,149 \mathrm{~mm}$. Nas condições otimizadas dos ensaios de concentração (15\% de sólidos na polpa e ângulo de inclinação da mesa igual a $3^{\circ}$ ), foram obtidas recuperações de manganês da amostra global, acima e abaixo de $0,074 \mathrm{~mm}$ de 77,81 e $62 \%$, respectivamente. Os teores de manganês e impurezas, nos concentrados, para as amostras estudadas, satisfizeram as especificações químicas dos produtos comercializados pela empresa.

Palavras-chave: Finos de minério de manganês, concentração em mesa oscilatória, tratamento de resíduos.

\begin{abstract}
This article presents the results of fine manganese ore from Morro da Mina Mine/RDM concentration studies using oscillatory table in order to obtain concentrates to be used in metallurgical industries. The global, the fractions above and below 0,074 mm samples manganese contents were 28,30; 26,84 and 31,31\%, respectively. It was observed that $80 \%$ of the particles in global sample were below 0,149 $\mathrm{mm}$. For the optimized table concentration test, solids pulp with $15 \%$ and table inclination angle of $3^{\circ}$, the manganese recoveries of the global, fraction above 0,074 and below 0,074 mm samples were of 77,81 and $62 \%$, respectively. The manganese and impurities contents in those concentrates satisfied the chemical specifications of Morro da Mina Mine/RDM products.
\end{abstract}

Keywords: manganese fine ores, concentration in oscillatory table, tiling processing. 


\section{Introdução}

O manganês é um elemento de transição da família do ferro. Em termos de abundância, perfaz 0,09\% em peso dos constituintes da crosta terrestre (Wills, 1992). Devido às suas características físico-químicas, esse elemento pode atuar como agente desoxidante, oxidante, dessulfurante e ser responsável por propriedades como maior maleabilidade, tenacidade e dureza dos aços. É também usado para obtenção de gusa, ferro-ligas e aços especiais. $\mathrm{Na}$ indústria não metalúrgica, o manganês é utilizado para fabricação de fertilizantes, pilhas eletrolíticas, cerâmicas, tintas, vernizes, reagentes químicos, entre outros udos (Gonçalves \& Serfaty, 1976; Ullmann, 1985).

Normalmente, o beneficiamento de minérios de manganês de elevados teores compreende etapas de fragmentação e classificação granulométrica. Para minérios de baixos teores, podem ser utilizados métodos de concentração, como gravimetria e flotação. Na Tabela 1, estão apresentadas algumas especificações de concentrados de manganês para a indústria metalúrgica.

Caneschi (1994) realizou estudos de caracterização e concentração do minério de manganês da Mina de Peruaçu, MG, onde um dos equipamentos de concentração utilizados foi a mesa concentradora. O minério foi dividido em duas frações granulométricas: $-0,84+0,21 \mathrm{~mm}$ e $-0,21+0,074 \mathrm{~mm}$. Na faixa granulométrica $-0,84+0,21 \mathrm{~mm}(-20+65$ mesh $)$, a alimentação tinha cerca de $35 \%$ em Mn, obtendo-se após o ensaio, um concentrado com uma média de $40 \%$ em Mn. Já para a faixa de $-0,21+0,074 \mathrm{~mm}(-65+200$ mesh) obteve-se um concentrado com teor de Mn em torno de $42 \%$, enquanto que, na alimentação, o teor de manganês estava em torno de $32 \%$.

Andrade (1978), tratando um minério por flotação da região de São João del-Rey, conhecido como gondito, contendo aproximadamente $35 \%$ de manganês, obteve concentrados com até $46 \%$ de Mn e recuperação metalúrgica de $80 \%$, para as seguintes condições: $\mathrm{pH}$ na fai- xa 3-4, usando HF, como modulador de pH, coletor Adogen $17298 \mathrm{~A}+83,600 \mathrm{~g} / \mathrm{t}$ (oleil-amina primária, produzida pela Ashland).

O beneficiamento do minério de manganês da Mineração Morro da Mina/ RDM faz-se através de britagem, classificação granulométrica e lavagem para remoção da fração fina (abaixo de $0,15 \mathrm{~mm}$ ) do minério, que, normalmente, vai para um tanque, onde é feita a decantação desses resíduos sólidos, que, após a separação sólido/líquido, são estocados, gerando um grande volume de finos ao longo da vida útil da mina, que, já ultrapassa um século de atividade. Logo, é de extrema importância, do ponto de vista ambiental e econômico, o desenvolvimento de processos e circuitos de concentração, que visem ao aproveitamento desses resíduos, quer para o emprego na indústria metalúrgica quer para outros fins. Dentro desse contexto, esse trabalho teve como objetivo concentrar os finos de minério de manganês da Mineração Morro da Mina/RDM, utilizando mesa oscilatória, visando a obter concentrado dentro das especificações químicas dos produtos comercializados por essa mineradora.

Tabela 1 - Especificações dos produtos da Mineração Morro da Mina/RDM.

\begin{tabular}{|c|c|c|c|c|}
\hline \multirow{2}{*}{ Produto } & \multirow{2}{*}{$\begin{array}{c}\text { Faixa } \\
\text { granulométrica }\end{array}$} & \multicolumn{3}{|c|}{ Especificação Química (\%) } \\
\hline & & Mn & $\mathrm{Fe}$ & $\mathrm{SiO}_{2}$ \\
\hline $\begin{array}{c}\text { Minério de Manganês } \\
\text { Sílico Carbonatado } \\
\text { Granulado }\end{array}$ & 6,3 a $71,0 \mathrm{~mm}$ & $30,5 \mathrm{~min}$ & $4,0 \max$ & 30,0 max \\
\hline $\begin{array}{c}\text { Minério de Manganês } \\
\text { Sílico Carbonatado Fino } \\
\text { - Tipo } 1\end{array}$ & 1,6 a $9,5 \mathrm{~mm}$ & $27,0 \mathrm{~min}$ & $4,5 \max$ & $29,0 \max$ \\
\hline $\begin{array}{c}\text { Minério de Manganês } \\
\text { Sílico Carbonatado Fino } \\
\text { - Tipo } 2\end{array}$ & 0 a $1,6 \mathrm{~mm}$ & $24,0 \mathrm{~min}$ & $4,5 \max$ & $29,0 \max$ \\
\hline $\begin{array}{c}\text { Minério de Manganês } \\
\text { Sílico Carbonatado Fino } \\
\text { - Tipo } 3\end{array}$ & 0 a $6,3 \mathrm{~mm}$ & $23,0 \mathrm{~min}$ & $6,0 \max$ & 35,0 max \\
\hline
\end{tabular}

\section{Materiais e métodos}

A amostra de finos de manganês provenientes da lavagem do minério de manganês da Mineração Morro da Mina/ RDM era constituída, essencialmente, pelos minerais de manganês rodocrosita e espessartina, quartzo, flogopita e clinocloro, huntita, anita e rutilo. Esses minerais foram determinados por difração de raios $\mathrm{X}$ (método do pó total). A distribuição granulométrica foi obtida por um peneiramento a úmido, usando a série Tyler de peneiras de 0,42 a $0,037 \mathrm{~mm}$ (35 a 400 mesh).

Os teores de $\mathrm{Mn}, \mathrm{Fe} \mathrm{SiO}_{2}, \mathrm{CaO}$, $\mathrm{Al}_{2} \mathrm{O}_{3}$ e $\mathrm{P}$, da amostra global e das frações granulométricas acima de $0,074 \mathrm{~mm}$ (+200mesh) e abaixo de 0,074 mm (-200mesh) e dos produtos dos ensaios de concentração, foram determinados por fluorescência de raios X.

Para os estudos de concentração gravítica em mesa oscilatória, foi utilizada uma mesa tipo Wilfley. As variáveis estudadas foram as faixas granulométricas $+0,074 \mathrm{~mm},-0,074 \mathrm{~mm}$ e amostra global; ângulo de inclinação da mesa igual a $3^{\circ}$ e $5^{\circ}$ e a porcentagem de sólidos de $15,20,25,30,35 \%$. As massas de amos- 
tra utilizadas para cada ensaio sempre foi de $2 \mathrm{~kg}$.

\section{Resultados e discussão}

A distribuição granulométrica da amostra de finos do minério de manganês da Mineração Morro da Mina/RDM está apresentada na Figura 1, onde se observa que $51,16 \%$ das partículas estavam abaixo de $0,074 \mathrm{~mm}$ (-200 mesh), sendo que graficamente foi obtido $\mathrm{d}_{50}=0,07 \mathrm{~mm}$. O $\mathrm{d}_{80}=0,15 \mathrm{~mm}$, isto é, $80 \%$ da amostra, encontrava-se abaixo de $0,150 \mathrm{~mm}$.

Pela Tabela 2, observa-se que os teores dos principais elementos analisados, $\mathrm{Mn}, \mathrm{Fe}$ e $\mathrm{SiO}_{2}$, ficaram dentro dos limites indicados nas especificações químicas $\left(\mathrm{Mn}_{\text {mínimo }}-23 \%, \mathrm{Fe}_{\text {máximo }}-6 \%\right.$ e $\mathrm{SiO}_{2 \text { máximo }}-35 \%$ ) dos produtos da Mineração Morro da Mina/RDM.

As Figuras 2, 3 e 4 apresentam os resultados dos ensaios de concentração para o ângulo de inclinação da mesa igual a $5^{\circ}$, onde se observa a diminuição da recuperação de manganês com o aumento da porcentagem de sólidos na polpa para as amostras global, acima de 0,074 $\mathrm{mm}$ e abaixo de $0,074 \mathrm{~mm}$. A porcentagem de sólidos em que foram obtidos os melhores resultados, para todas as faixas granulométricas, foi de $15 \%$. Nesse caso, as recuperações de manganês, para a amostra global, $+0,074 \mathrm{e}-0,074 \mathrm{~mm}$, ficaram em torno de 59,47 e $38 \%$, respectivamente. Os teores de manganês nos concentrados decresceram ligeiramente com o aumento da porcentagem de sólidos. Pode-se afirmar que essa diminuição dos teores não foi significativa, podendo perfeitamente estar dentro da faixa de erro de análise, pois, para todos os ensaios, nas diferentes frações granulométricas, os teores dos concentrados ficaram em torno de $32 \%$, não ocorrendo grande enriquecimento, uma vez que o teor de manganês na alimentação da amostra global, $+0,074$ e $0,074 \mathrm{~mm}$, foi de 28,$3 ; 26,8$ e $31,3 \%$, respectivamente.

Com ângulo de inclinação da mesa igual a $3^{\circ}$, Figura 5 , a recuperação de manganês, para todas as faixas granulo-

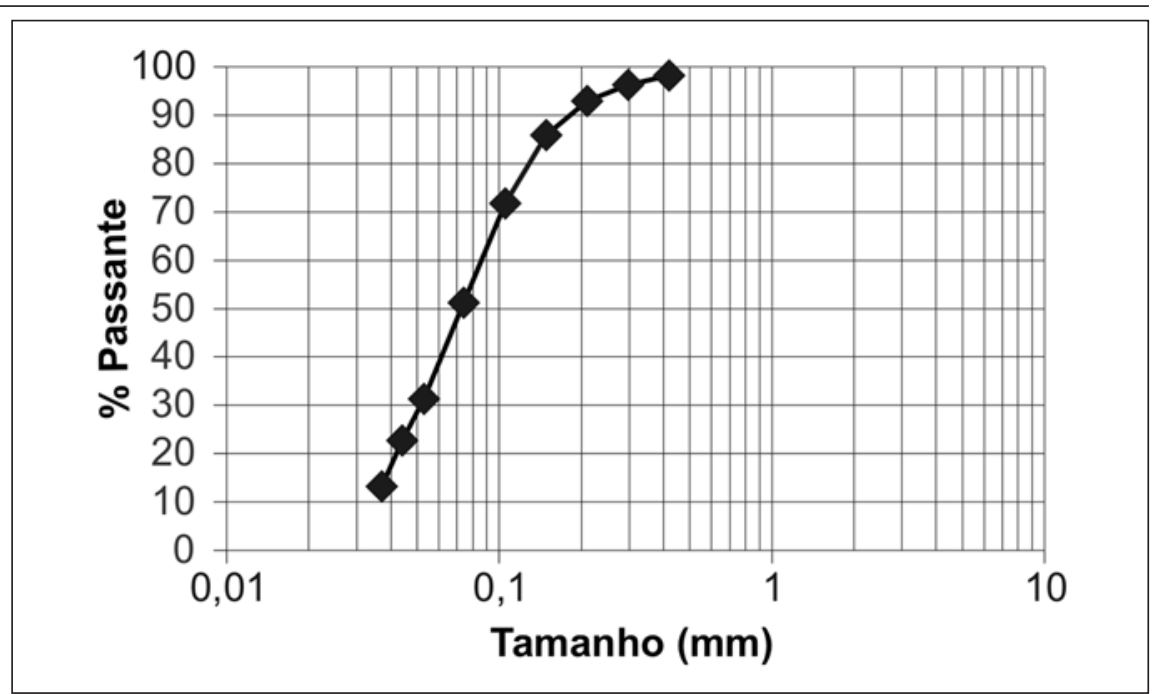

Figura 1 - Distribuição granulométrica dos resíduos de minério de manganês da Mineração Morro da Mina /RDM.

Tabela 2 - Resultados da análise química, dos principais elementos e compostos, da amostra global e das frações granulométricas $+0,074$ e - $0,074 \mathrm{~mm}$ de finos de manganês da Mineração Morro da Mina/RDM.

\begin{tabular}{c|c|c|c|c|c|c}
\hline \multirow{2}{*}{ Amostra } & \multicolumn{7}{|c}{ Teor } \\
\cline { 2 - 7 } & $\mathbf{M n}$ & $\mathbf{F e}$ & $\mathrm{SiO}_{2}$ & $\mathbf{A l}_{2} \mathrm{O}_{3}$ & $\mathbf{C a O}$ & $\mathbf{P}$ \\
\hline Amostra Global & 28,30 & 3,67 & 28,10 & 9,30 & 2,63 & 0,080 \\
\hline $\mathbf{+ 0 , 0 7 4} \mathbf{~ m m}$ & 26,84 & 3,73 & 29,71 & 9,59 & 2,33 & 0,097 \\
\hline $\mathbf{- 0 , 0 7 4} \mathbf{~ m m}$ & 31,31 & 3,35 & 22,77 & 8,94 & 2,33 & 0,098 \\
\hline
\end{tabular}

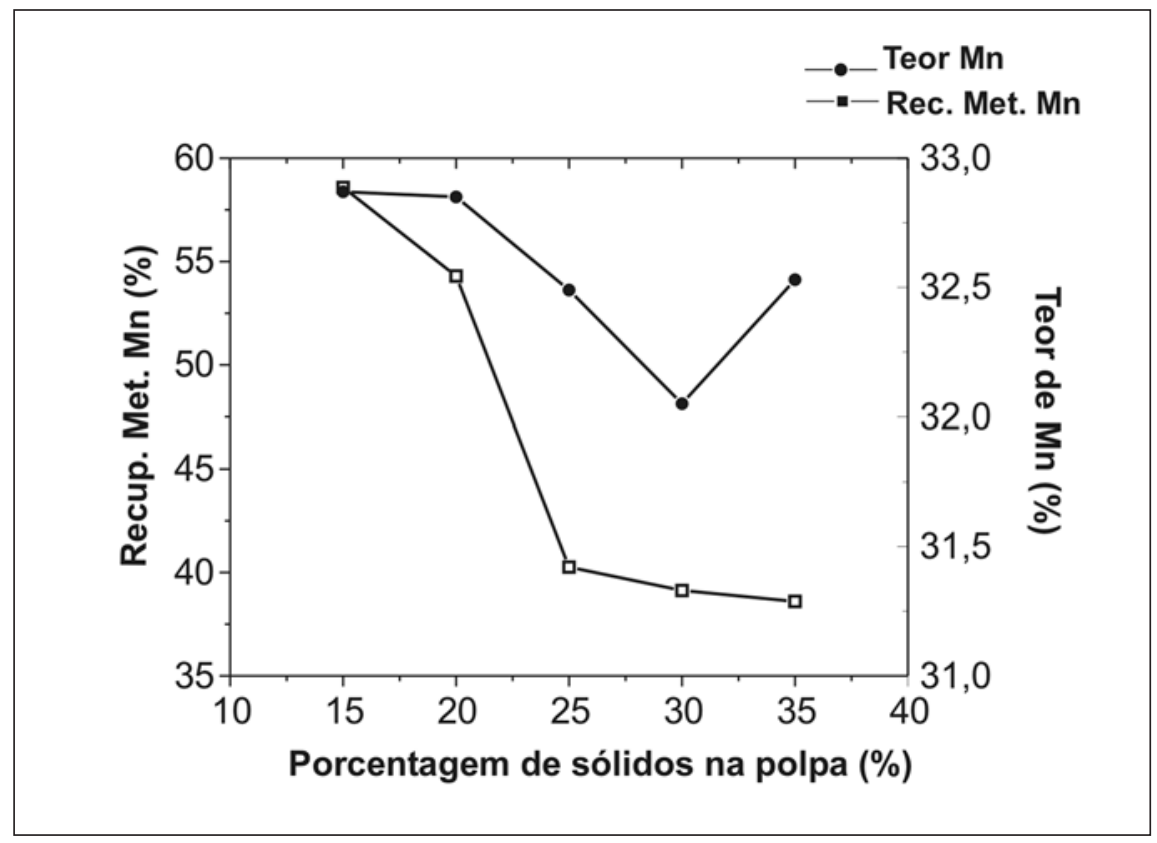

Figura 2 - Influência da porcentagem de sólidos na polpa sobre a recuperação metalúrgica e teor de manganês da amostra global, para o ângulo de inclinação da mesa de $5^{\circ}$. 
métricas testadas, mostrou-se sempre maior que a recuperação nos ensaios com a mesa com ângulo de inclinação de $5^{\circ}$, chegando a $77 \%$, para a amostra global, $81 \%$, para a fração acima de 0,074 $\mathrm{mm}$ e $62 \%$, para a fração abaixo de $0,074 \mathrm{~mm}$, ou seja, acréscimos de 20,33 e $24 \%$, respectivamente para as amostras ensaiadas. O teor de manganês ficou em torno de $31,50 \%$, não ocorrendo grande enriquecimento, uma vez que o teor de manganês da alimentação da amostra global foi de 28,3\%, +0,074 foi de 26,8 e $-0,074 \mathrm{~mm}$ foi de $31,3 \%$.

Em termos de teor de manganês nos concentrados, para todos os ensaios em mesa oscilatória, observa-se que a relação de enriquecimento foi pequena, mas há de se salientar que, para todos os concentrados obtidos, os teores de manganês estavam bem acima do valor mínimo $\left(\mathrm{Mn}_{\text {min. }}-23 \%\right)$ desse elemento apresentado pelas especificações químicas dos produtos da Mineração Morro da Mina/ RDM (Tabela 1).

Observa-se, pela Figura 5, que, tanto o teor, quanto a recuperação de manganês da fração acima de $0,074 \mathrm{~mm}$, foram similares aos valores obtidos com a amostra global. Para a fração granulométrica menor que $0,074 \mathrm{~mm}$, obteve-se recuperação bem menor do que nos casos anteriores. Isto pode estar relacionado com a faixa de eficiência do equipamento, que, segundo a literatura, está acima de $0,074 \mathrm{~mm}$.

Os teores das principais impurezas, nos concentrados de todos os ensaios realizados na mesa oscilatória, $\mathrm{Fe}, \mathrm{SiO}_{2}$, $\mathrm{Al}_{2} \mathrm{O}_{3}, \mathrm{CaO}$ e $\mathrm{P}$, não apresentaram variações significativas, com a variação da porcentagem de sólidos na polpa. A Tabela 3 apresenta o valor médio das principais impurezas nos concentrados, para a amostra global e para as frações granulométricas $+0,074$ e $-0,74 \mathrm{~mm}$, nos ensaios com ângulo de inclinação da mesa igual a $5^{\circ}$ e $3^{\circ}$.

\section{Conclusões}

- A análise química dos finos do minério de manganês mostrou que os teores dos principais elementos

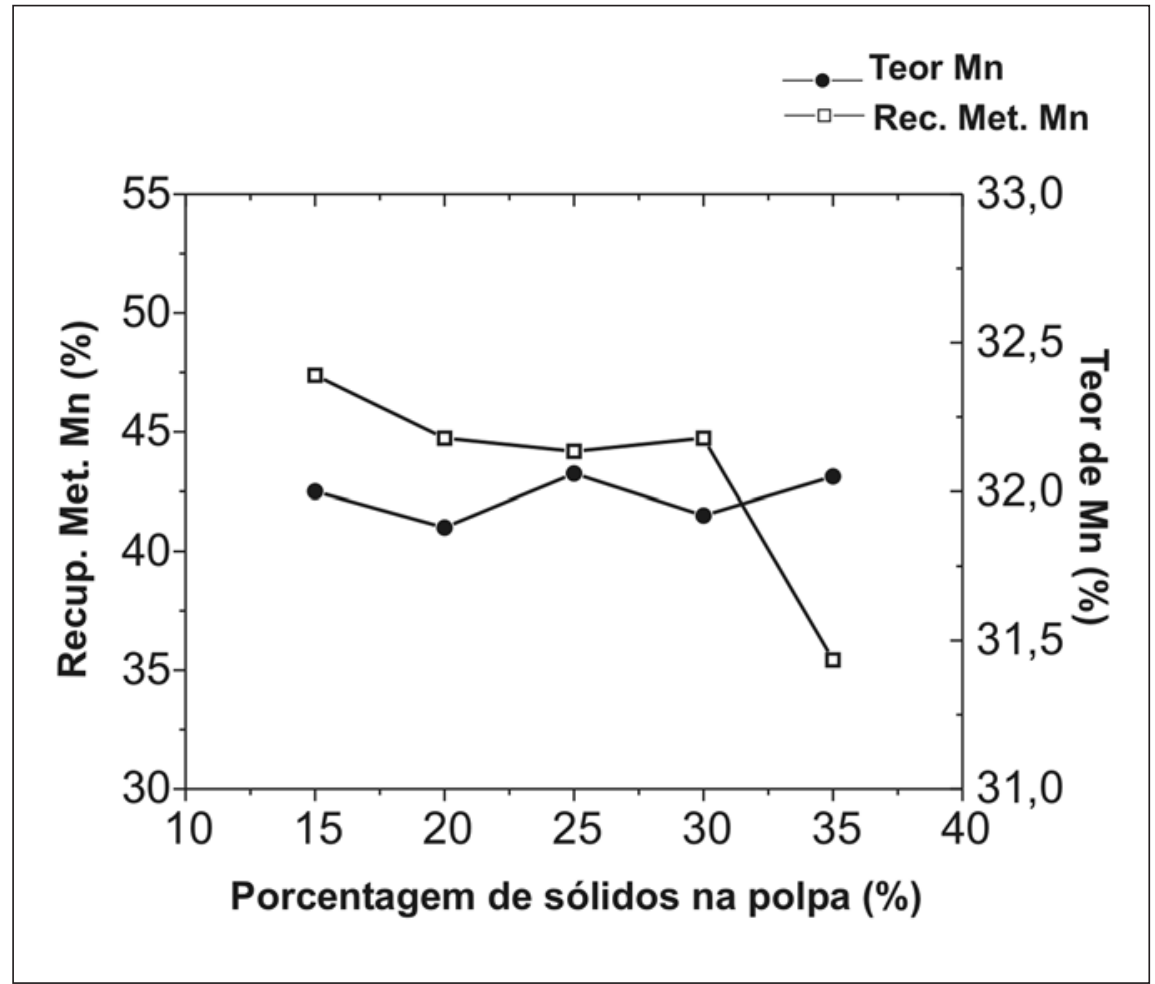

Figura 3 - Influência da porcentagem de sólidos na polpa sobre a recuperação metalúrgica e teor de manganês para fração granulométrica $+0,074 \mathrm{~mm}$, para ângulo de inclinação da mesa de $5^{\circ}$.

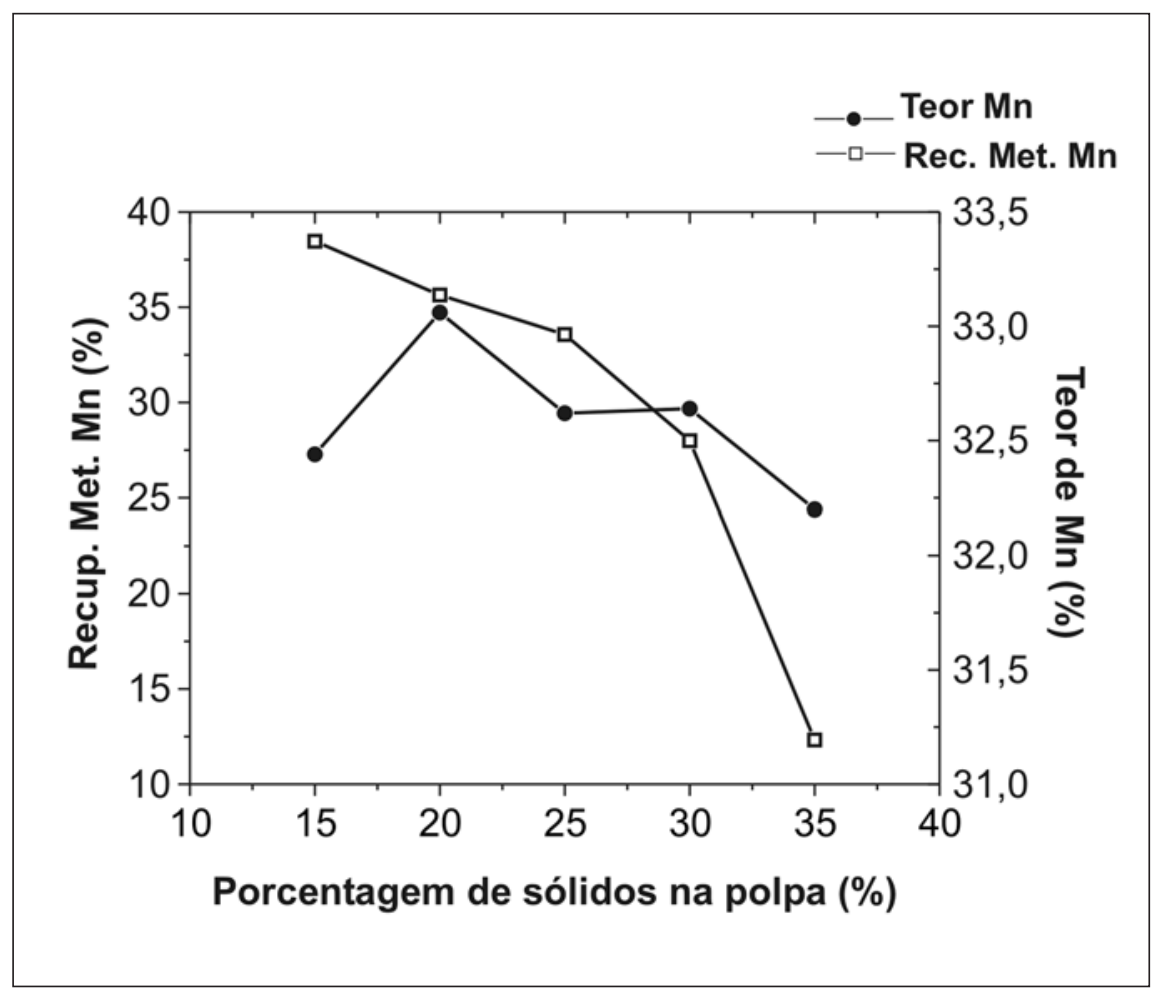

Figura 4 - Influência da porcentagem de sólidos na polpa sobre a recuperação metalúrgica e teor de manganês para fração granulométrica $-0,074 \mathrm{~mm}$, para ângulo de inclinação da mesa de $5^{\circ}$. 
analisados, $\mathrm{Mn}, \mathrm{Fe}$ e $\mathrm{SiO}_{2}$, foram 28,$3 ; 3,67$ e $28,10 \%$, respectivamente, e estavam dentro dos limites indicados pelas especificações químicas $\left(\mathrm{Mn}_{\text {mín. }}=23 \%, \mathrm{Fe}_{\text {máx }}=6 \% \mathrm{e}\right.$ $\left.\mathrm{SiO}_{2 \text { máx }}=35 \%\right)$ dos produtos da Mineração Morro da Mina/RDM.

- A mudança do ângulo de inclinação da mesa de $5^{\circ}$ para $3^{\circ}$ acarretou um grande aumento na recuperação de manganês nos concentrados, chegando a $77 \%$, para a amostra global, $81 \%$, para a fração acima de 0,074 $\mathrm{mm}$ e $62 \%$, para a fração abaixo de $0,074 \mathrm{~mm}$, ou seja, acréscimos de 20 , 33 e $24 \%$, respectivamente.

- Em conjunto, os maiores valores da relação de enriquecimento e recuperação de manganês são obtidos para a fração granulométrica acima de $0,074 \mathrm{~mm}$ (recuperação de Mn de $81 \%$ ) e amostra global (recuperação de Mn de 77\%), nos ensaios com $15 \%$ de sólidos na polpa e a mesa com ângulo de inclinação igual a $3^{\circ}$.

\section{Agradecimentos}

As autoras agradecem à CAPES, pela concessão de bolsa de estudo, e à Mineração Morro da Mina/RDM, pela concessão da amostra e financiamento do projeto.

\section{Referências Bibliograficas}

ANDRADE, V. L. L. Estudos de Concentração do Gondito. Belo Horizonte: Escola de Engenharia, Universidade Federal de Minas Gerais, 1978. 70p. (Dissertação de Mestrado em Engenharia Metalúrgica e de Minas).

CANESCHI, G. M. M. Estudos de concentração do minério de manganês da Mina de Peruaçu MG. Belo Horizonte: Escola de Engenharia, Universidade Federal de Minas Gerais, 1994. 97p. (Dissertação de Mestrado em Engenharia Metalúrgica e de Minas).

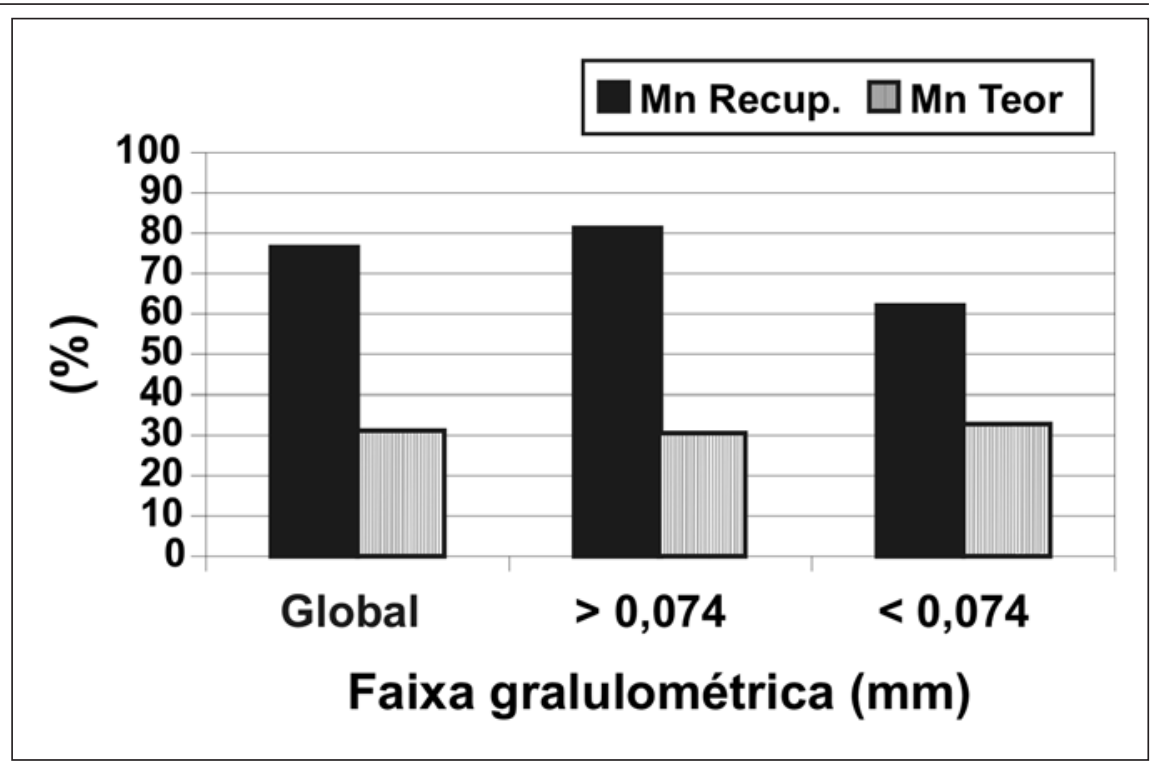

Figura 5 - Recuperação metalúrgica e teor de manganês nos concentrados para as diferentes frações granulométricas com $15 \%$ de sólidos na polpa e ângulo de inclinação da mesa igual a $3^{\circ}$.

Tabela 3 - Valores médios dos teores das principais impurezas nos concentrados das diferentes frações granulométricas com ângulo de inclinação da mesa igual a $5^{\circ} \mathrm{e} 3^{\circ}$.

\begin{tabular}{c|c|c|c|c|c|c}
\hline \multirow{2}{*}{ Amostra } & \multirow{2}{*}{$\begin{array}{c}\text { Ângulo de } \\
\text { inclinação } \\
\text { da mesa }\end{array}$} & \multicolumn{5}{|c}{ Teor(\%) } \\
\cline { 3 - 7 } & $5^{\circ}$ & 3,6 & 25,9 & 11,4 & 2,1 & 0,07 \\
\hline $\begin{array}{c}\text { Amostra } \\
\text { Global }\end{array}$ & $5^{\circ}$ & $\mathrm{Al}_{2} \mathrm{O}_{3}$ & $\mathbf{C a O}$ & $\mathbf{P}$ \\
\hline$+0,074 \mathrm{~mm}$ & $5^{\circ}$ & 3,5 & 28,0 & 12,9 & 2,1 & 0,09 \\
\hline$-0,074 \mathrm{~mm}$ & $5^{\circ}$ & 3,6 & 27,0 & 13 & 2,2 & 0,08 \\
\hline $\begin{array}{c}\text { Amostra } \\
\text { Global }\end{array}$ & $3^{\circ}$ & 3,6 & 27,0 & 10,3 & 2,4 & 0,07 \\
\hline$+0,074 \mathrm{~mm}$ & $3^{\circ}$ & 3,5 & 29,0 & 10,6 & 2,3 & 0,04 \\
\hline$-0,074 \mathrm{~mm}$ & $3^{\circ}$ & 3,6 & 25,3 & 11,3 & 2,3 & 0,05 \\
\hline
\end{tabular}

GONÇALVES, E., SERFATY,A. Perfil analítico do manganês. Brasília: Departamento Nacional da Produção Mineral/DNPM, 1976. Boletim n. 37. 149p.

ULLMANN, F. Manganese and manganese alloys. In: Encyclopedia of Industrial Chemistry. Germany, VCH, Weinhein, 1985. v. 16 A, p. 77-133.

WILLS, B. A. Mineral processing technology. New York: Pergamon Press, 1992. $855 \mathrm{p}$.

Artigo recebido em 22/03/2005 e aprovado em 20/07/2005. 